\title{
Penerapan model pembelajaran Inquiry Pictorial Riddle untuk meningkatkan keaktifan siswa
}

\author{
Maghfira Febriana ${ }^{\mathbf{1}}$, Hasan Al Asy'ari ${ }^{\mathbf{1}}$, Bambang Subali ${ }^{\mathbf{1}}$, Ani Rusilowati \\ ${ }^{1}$ Prodi Pendidikan Fisika, Program Pascasarjan Universitas Negeri Semarang, Semarang 50229, \\ Indonesia \\ E-mail: firafebria@gmail.com; hasanalasyari22@gmail.com; bambangfisika@mail.unnes.ac.id; \\ rusilowati@yahoo.com
}

Received: 0612 2017. Revision: 2901 2018. Accepted: 01022018

\begin{abstract}
Abstrak
Penelitian ini merupakan penelitian tindakan kelas (PTK). Model pembelajaran inquiry berbasis pictorial riddle memanfaatkan media visual sebagai media pembelajaran. Tujuan dari penelitian ini adalah meningkatkan keaktifan siswa dalam proses pembelajaran materi gerak lurus. Analisis data menggunakan teknik kualitatif. Tahap pra-siklus menunjukkan keaktifan siswa mengajukan pertanyaan 5\%, keaktifan siswa menjawab pertanyaan 5\%, dan keaktifan siswa dalam diskusi kelompok $12,5 \%$. Pada siklus I hasil keaktifan siswa mengajukan pertanyaan $40 \%$, keaktifan siswa menjawab pertanyaan $6,7 \%$, dan keaktifan siswa diskusi kelompok $62,5 \%$. Hasil siklus I menunjukkan belum ada peningkatan signifikan pada keaktifan siswa menjawab pertanyaan. Siklus II dilaksanakan dengan menambah pemberian reward atau penghargaan bagi siswa aktif menjawab pertanyaan. Pada siklus II hasil persentase keaktifan siswa mengajukan pertanyaan $43 \%$, keaktifan siswa menjawab pertanyaan 33,3\%, dan keaktifan siswa diskusi kelompok 75\%. Berdasarkan analisis data diperoleh simpulan bahwa model pembelajaran inquiry pictorial riddle dapat digunakan untuk meningkatkan keaktifan siswa dalam proses pembelajaran.
\end{abstract}

Kata Kunci: inquiry; pictorial riddle; keatifan

\section{The Implementation of Inquiry Pictorial Riddle Learning Model to Increase Students' Activity}

\begin{abstract}
The research is a classroom action research. Inquiry learning model based on pictorial riddle using visual media as a learning media. The purpose of this study is to increase the students' activity in the learning process of linear motion's material. The data analysis use qualitative techniques. Pre-cycle stage show activity of students asked questions 5\%, active students answered questions 5\%, and the active students in group discussions 12.5\%. First cycle shows the results of students asked questions 40\%, students answered questions $6.7 \%$, and students' activity group discussions $62.5 \%$. There's no significant increase to the activity of students answered questions for the results of the first cycle showed. The second cycle carried out by giving a reward or appreciation for active students to answer individual questions. The percentage of active students inquiry the question of second cycle are $43 \%$, active students answered questions $33.3 \%$, and student activity group discussions $75 \%$. Based on the data analysis, it is concluded that inquiry learning model based pictorial riddle can be used to increase the students' activity in learning process.
\end{abstract}

Keywords: inquiry; pictorial riddle; activity 


\section{PENDAHULUAN}

Keberhasilan proses pembelajaran dapat terlihat dari ketercapaian kompetensi belajar siswa. Kompetensi belajar meliputi proses dan hasil belajar. Pembelajaran dikatakan berhasil dan berkualitas apabila seluruhnya atau setidak-tidaknya sebagian besar peserta didik terlibat secara aktif, baik fisik, mental maupun sosial dalam proses pembelajaran, di samping menunjukkan kegairahan belajar yang tinggi, semangat belajar yang besar, dan rasa percaya pada diri sendiri. Berdasarkan hal tersebut di atas, upaya guru dalam mengembangkan keaktifan belajar siswa sangatlah penting, sebab keaktifan belajar siswa menjadi penentu bagi keberhasilan pembelajaran yang dilaksanakan.

Menurut Hamalik (2005, p.172), belajar tidak cukup hanya dengan mendengar dan melihat tetapi harus dengan melakukan aktivitas yang lain diantaranya membaca, bertanya, menjawab, berpendapat, mengerjakan tugas, menggambar, mengkomunikasikan, presentasi, diskusi, menyimpulkan, dan memanfaatkan peralatan. Dalam pembelajaran, guru menyajikan permasalahan matematika dan mendorong siswa untuk mengidentifikasi permasalahan, mencari pemecahan, menyimpulkan hasilnya, kemudian mempresentasikannya. Tugas guru sebagai fasilitator dan pembimbing adalah memberikan bantuan dan arahan. Ketika siswa menemukan permasalahan dalam menyelesaikan tugas, selain berinteraksi dengan guru, siswa juga dapat bertanya dan berdiskusi dengan siswa lain. Siswa dikatakan belajar dengan aktif jika mereka mendominasi aktivitas pembelajaran. Siswa secara aktif menggunakan pemikirannya, baik untuk menemukan ide pokok dari materi, memecahkan persoalan, atau mengaplikasikan apa yang dipelajari. Aktivitas dalam suatu pembelajaran bukan hanya siswa yang aktif belajar tetapi di lain pihak, guru juga harus mengorganisasi suatu kondisi yang dapat mengaktifkan siswa dalam belajar. Oleh karena itu, salah satu usaha yang dapat dilakukan guru adalah merencanakan dan menggunakan model pembelajaran yang dapat mengkondisikan siswa agar belajar secara aktif.
Pendekatan psikologi kognitif dalam teori pengajaran dipelopori oleh Jerome Bruner seorang ahli psikologi belajar dan psikologi perkembangan. Menurut Bruner, dalam proses belajar dapat dibedakan tiga fase atau episode, yakni (1) enaktif, (2) ikonik (3) simbolik (pengkajian pengetahuan). Enaktif, dalam tiap pelajaran kita peroleh sejumlah informasi ada yang menambah pengetahuan yang telah kita miliki, ada yang memperhalus dan memperdalamnya, ada pula informasi yang bertentangan dengan apa yang telah kita ketahui sebelumnya, misalnya bahwa tidak ada energi yang lenyap. Ikonik, informasi itu harus dianalisis diubah atau ditransformasi kedalam bentuk yang lebih abstrak atau konseptual agar dapat digunakan untuk halhal yang lebih luas. Simbolik, kemudian kita nilai hingga manakah pengetahuan yang kita peroleh dan transformasi itu bisa dimanfaatkan untuk memahami gejala-gejala lain. Ketiga tahap tersebut selalu ada dalam proses belajar. Masalah yang timbul ialah berapa banyak informasi diperlukan agar dapat ditransformasikan. Lama tiap tahap tidak selalu sama bergantung pada hasil yang diharapkan, motivasi murid belajar, minat, keinginan untuk mengetahui dan dorongan untuk menemukan sendiri (Del'an, 2013, p.2$3)$.

Motivasi belajar siswa dapat meningkat apabila kondisi suasana bervariasi, menarik, dan menyenangkan dengan pembelajaran tidak monoton sehingga siswa tidak jenuh (Sari et al, 2017, p.110). Guru bertugas mengoptimalkan kemampuan dasar siswa agar berkembang secara efektif. Seorang guru harus dapat menjadi fasilitator siswa, agar siswa tidak mengalami kesulitan dan kebosanan dalam kegiatan belajar mengajar. Metode inquiry merupakan salah satu solusinya. Pengajaran inquiry harus meliputi pengalaman belajar untuk menjamin bahwa siswa dapat mengembangkan proses inquiry (Sochibin, 2009, p.97). Pembelajaran inquiry merupakan kegiatan pembelajaran yang melibatkan secaramaksimal seluruh kemampuan siswa untuk mencari dan menyelidiki sesuatu (benda, manusia atau peristiwa) secara sistematis, kritis, logis, analitis sehingga mereka dapat merumuskan sendiri penemuannya dengan penuh percaya diri (Susilawati, 2014, p.8). Proses belajar 
inquiry memberikan kesempatan siswa melakukan penyelidikan terlebih melalui kegiatan laboratorium atau pengamatan kejadian, berinteraksi dengan teman, menumbuhkan percaya diri, dan sikap aktif (Gormally et al, 2009, p.14). Pembelajaran inquiry memberikan banyak manfaat bagi siswa, namun pada kenyataannya tetap terdapat kendala yaitu siswa yang cenderung pasif saat pembelajaran, untuk itu dibutuhkan media visual sebagai alat menarik perhatian dan motivasi siswa serta membuat materi lebih mudah dipahami (Syafura, 2017, p.624).

Metode pictorial riddle adalah suatu metode atau teknik untuk mengembangkan aktivitas siswa dalam diskusi kelompok kecil maupun besar, melalui penyajian masalah yang disajikan dalam bentuk ilustrasi. Suatu riddle biasanya berupa gambar, baik di papan tulis, papan poster, maupun diproyeksikan dari suatu transparansi, kemudian guru mengajukan pertanyaan yang berkaitan dengan riddle itu (Kristianingsih, 2010, p.1011).

Setiap orang yang belajar harus aktif sendiri, tanpa ada aktivitas, maka proses belajar tidak mungkin terjadi, dengan kata lain bahwa dalam belajar sangat diperlukan adanya aktivitas. Tanpa aktivitas, belajar itu tidak mungkin berlangsung dengan baik. Maksud

dari aktivitas belajar adalah aktivitas yang bersifat fisik maupun mental, dalam kegiatan belajar kedua aktivitas itu harus selalu terkait (Murti, 2015, p.98). Indikator keaktifan siswa dalam pembelajaran meliputi antusias siswa dalam mengikuti pembelajaran, pemahaman konsep dari materi yang dipelajari, interaksi siswa dengan guru, penyelesaian tugas secara individual, dan penyelesaian tugas secara berkelompok (Mardiyan, 2012, p.153).

Berdasarkan hasil wawancara terhadap guru mata pelajaran fisika kelas X SMA Kesatrian 2 Semarang ditemukan permasalahan tentang rendahnya keaktifan siswa untuk mengajukan pertanyaan dalam pembelajaran sangat rendah sekitar 5\%, keaktifan dalam diskusi kelompok hanya $25 \%$ siswa, dan keaktifan mengerjakan soal
3\% siswa. Pembelajaran inquiry merupakan pembelajaran yang menuntut siswa belajar aktif. Pembelajaran inquiry berbasis pictorial riddle memanfaatkan gambar sebagai media pembelajaran. Gambar disajikan berupa visualisasi materi pelajaran untuk merangsang siswa berpikir kritis dan aktif. Siswa terlibat langsung dalam diskusi dan pemecahan masalah dari gambar. Keterlibatan siswa secara langsung tersebut diharapkan dapat menjandikan siswa lebih aktif dalam aktivitas belajarnya. Model pembelajaran ini telah digunakan pada penelitian terdahulu untuk mata pelajaran IPA-Fisika tingkat SMP. Berdasarkan hasil penelitian yang berjudul Peningkatan Aktivitas dan Hasil Belajar IPA-Fisika Pada Siswa Kelas VIII C SMP Negeri 7 Jember Tahun Ajaran 2014/2015 dengan Model Inkuiri melalui Teknik Pictorial Riddle terdapat peningkatan keaktifan siswa setelah diterapkan model pembelajaran inquiry pictorial riddle (Permatasari, 2016, p.275). Berdasarkan latar belakang tersebut, penulis mengambil judul "Penerapan Model Pembelajaran Inquiry Pictorial Riddle untuk Meningkatkan Keaktifan Siswa" pada materi gerak lurus.

\section{METODE}

Jenis penelitian yang dilakukan adalah Penelitian Tindakan kelas (PTK). Penelitian ini bertujuan untuk meningkatkan keaktifan siswa melalui penerapan model inquiry dengan teknik pictorial riddle. Subjek dalam penelitian adalah siswa kelas X SMA Kesatrian 2 Semarang dengan jumlah siswa 35 orang. Penelitian dilaksanakan pada semester I tahun ajaran 2017/2018.

Pelaksanaan penelitian terdiri dari II siklus yaitu siklus 1 dan siklus II setiap siklus terdiri dari empat tahapan yang harus dijalani yaitu perencanaan, pelaksanaan tindakan, pengamatan, dan refleksi. Setiap akhir dari siklus diadakan latihan soal untuk mengetahui tingkat keaktifan siswa secara individu. Siswa dikategorikan aktif secara individu jika memenuhi indikator yaitu siswa berani mengacungkan tangan, maju ke depan kelas, dan menuliskan jawaban di papan 


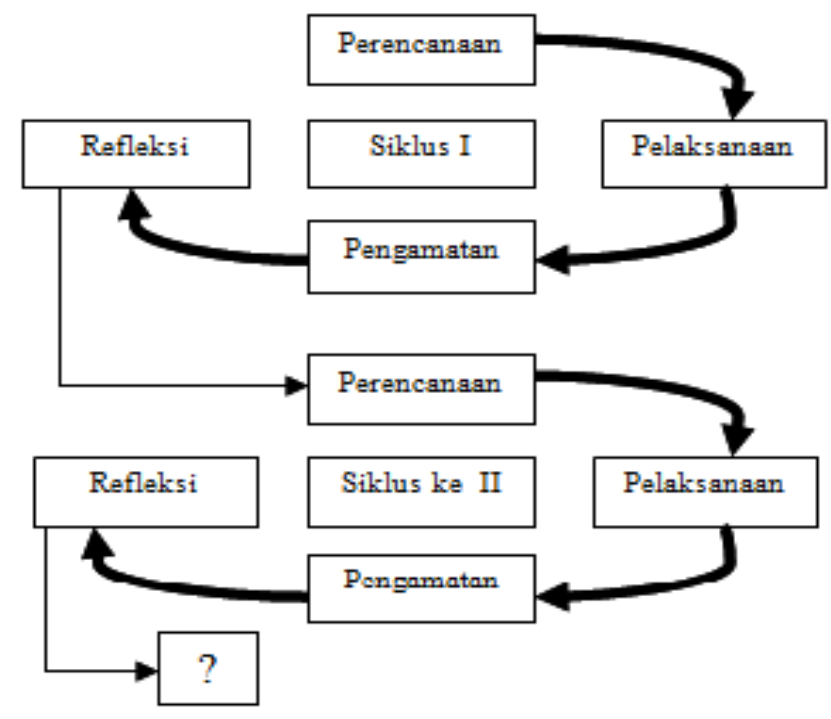

Gambar 1. Siklus Penelitian

Teknik pengumpulan data dan instrumen pengumpulan data yaitu teknik observasi dengan instrumen lembar observasi untuk menilai kegiatan siswa selama proses pembelajaran berlangsung dengan menerapkan model pembelajaran inquiry dengan teknik pictorial riddle.

Teknik analisis data yang digunakan adalah analisis kuantitatif data informasi berupa simbol angka atau bilangan persentase keaktifan siswa. Berdasarkan simbol-simbol angka tersebut perhitungannya dengan cara mengumpulkan data, menyajikan data, mengolah data serta membuat kesimpulan. Sedangkan teknik analisis data kualitatif digunakan menganalisis data hasil lembar observasi kegiatan guru dan siswa dengan cara penyajian data dan membuat kesimpulan.

Hasil pengolahan data dianalisis secara deskriptif komparatif yaitu membandingkan kondisi pra siklus, siklus I dan siklus II. Siklus I menggunakan lembar diskusi berupa gambar (pictorial riddle) daan siklus II bahan diskusi dari tampilan gambar animasi melalui proyektor. Untuk mengetahui keberhasilan dalam penelitian ini ditentukan indikator kinerja yaitu indikator proses dan hasil. Kemudian untuk keaktifan siswa dapat dikatakan berhasil jika pada masing-masing aspek telah memenuhi minimal $30 \%$ dari total siswa yang hadir aktif mengikuti kegiatan pembelajaran.

\section{HASIL DAN PEMBAHASAN}

Siklus I dilakukan dengan menerapkan model pembelajaran inquiry pictorial riddle sehingga bisa mendorong siswa melakukan diskusi dan aktif menyampaikan pendapat atau pertanyaan. Model pembelajaran inquiry pictorial riddle ditambah pemberian reward atau penghargaan bagi siswa yang aktif diterapkan pada siklus II, diharapkan keaktifan siswa yang masih rendah pada siklus I dapat meningkat dengan adanya pemberian penghargaan bagi siswa aktif pada siklus II.

Berdasarkan hasil penelitian tindakan kelas dengan penerapan model inquiry pictorial riddle terhadap keaktifan siswa terdapat peningkatan dari aspek antusias siswa, keaktifan individu dan keaktifan kelompok dari siklus I ke siklus II ditunjukkan pada Gambar 2. 


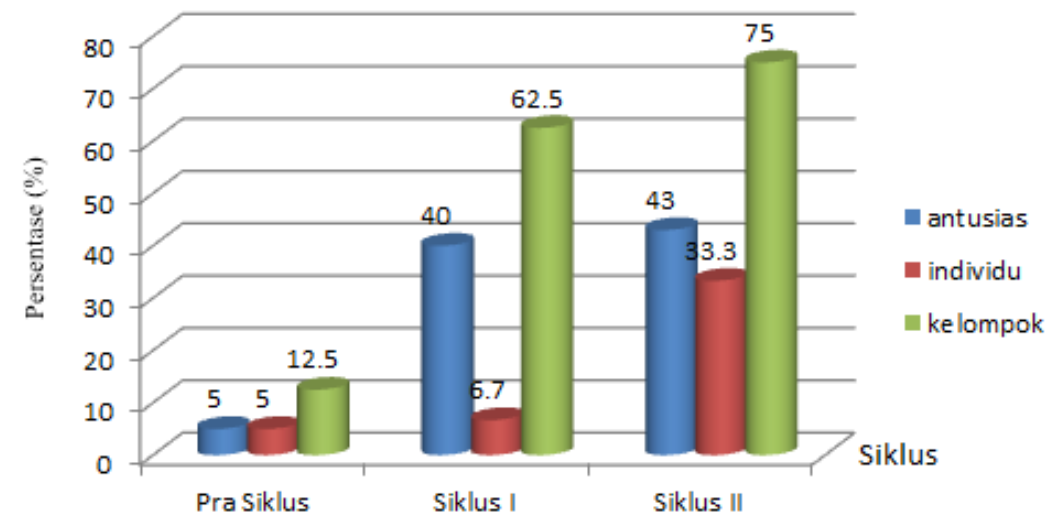

Gambar 2. Data Keaktifan Siswa

Pada grafik 1, data prasiklus didapat dari observasi dan wawancara langsung kepada guru tentang keaktifan siswa dalam pembelajaran. Pada tahap prasiklus, siswa belum menunjukkan keaktifan dari aspek antusian siswa hanya 2 dari 35 siswa (5\%), keaktifan individu hanya 2 dari 35 siswa (5\%), dan keaktifan kelompok hanya 1 dari 8 kelompok $(12,5 \%)$ dalam mengikuti pembelajaran.

Pada siklus I diterapkan model pembelajaran inquiry pictorial riddle dengan berbantuan video terdapat perubahan keaktifan siswa dalam aspek antusias siswa menjadi 12 siswa dari 30 siswa yang hadir (40\%) dan penugasan kelompok menjadi 5 kelompok dari 8 kelompok $(62,5 \%)$. Tingkat keaktifan siswa menyelesaikan tugas individu masih cukup rendah yaitu 2 siswa dari 30 siswa yang hadir(6,7\%). Hasil persentase keaktifan siswa pada aspek mengerjakan tugas individu pada prasiklus dan siklus I tidak mengalami perubahan signifikan.

Siklus II menerapkan model inquiry pictorial riddle dengan gambar animasi dan memberikan reward bagi siswa yang aktif dalam mengerjakan tugas individu. Target yang ingin dicapai pada siklus II yaitu pada indikator keaktifan siswa bagian penyelesaian tugas individu. Hasil siklus II menunjukan adanya peningkatan keaktifan siswa dalam hal mengerjakan tugas individu yaitu 10 siswa dari 30 siswa yang hadir(33,3\%). Pada model pembelajaran inquiry pictorial riddle siswa diajak untuk diskusi agar dapat berbagi pengetahuan dengan teman-temannya melalui permasalahan berupa teka-teki gambar yang diberikan oleh guru maupun melakukan pengamatan.

Peningkatan keaktifan belajar tersebut dikarenakan siswa sudah semakin bisa beradaptasi dengan penerapan model inquiry pictorial riddle. Model belajar inquiry memberikan keleluasaan kepada siswa untuk belajar melalui proses inquiry yaitu menemukan sendiri sebagaimana seorang ilmuan atau peneliti bekerja (Ratnasari, 2015, p.8). Hasil penelitian pembelajaran IPA fisika terhadap perangkat pembelajaran fisika melalui model pembelajaran inquiry dengan metode pictorial riddle termasuk dalam kategori efektif untuk diterapkan dalam proses pembelajaran mengajak siswa aktif, meningkatkan hasil belajar siswa, dan kemampuan berpikir kritis siswa (Imelda, 2013, p.39). Model pembelajaran inquiry pictorial riddle mampu menumbuhkan motivasi belajar, meningkatkan interaksi antar sesama siswa, menciptakan keaktifan siswa, dan melatih siswa untuk berfikir kritis (Fauziah, 2014, p.88). Hal ini dikarenakan model pembelajaran inquiry pictorial riddle lebih mengajak siswa melakukan aktifitas agar dapat menganalisis fenomena berdasarkan materi yang dipelajari melalui diskusi dan presentasi.

\section{SIMPULAN}

Model pembelajaran inquiry pictorial riddle dapat digunakan untuk meningkatkan keaktifan siswa kelas $\mathrm{X}$ MIPA 3 SMA Kesatrian 2 Semarang tahun ajaran 2017/2018 dalam proses pembelajaran. Berdasarkan hasil penelitian dan pembahasan 
maka saran yang dapat diberikan adalah model pembelajaran inquiry pictorial riddle dapat dijadikan alternatif untuk meningkatkan keaktifan siswa, penggunaan gambar atau animasi harus dipilih sesuai materi dan mampu menarik perhatian siswa sehingga meningkatkan motivasi siswa untuk memahami materi pelajaran.

\section{DAFTAR PUSTAKA}

Del'an, Y.J, dan Bistari. (2013). Peningkatan Aktivitas Belajar Siswa Kelas VII SMP pada Bilangan Pecahan dengan Teori Bruner. Jurnal Pendidikan dan Pembelajaran, 2(12), 1-15.

Fauziah, Mahrizal, dan Gusnedi. (2014). Penerapan Model Pembelajaran Inkuiri Tipe Pictorial Riddle dalam Bentuk Animasi terhadap Hasil Belajar Fisika Siswa Kelas XI SMA Negeri 2 Batusangkar. Pillar of Physics Education, 4(2014), 81-88.

Gormally, Cara et al. (2009). Effects of Inquiry-based Learning on Students' Science Literacy Skills and Confidence. International Journal for the Scholarship of Teaching and Learning (IJSOTL), 2(3), 1-22.

Hamalik, O. (2005). Teknik Pengukuran dan Evaluasi Pendidikan. Bandung: Mandar Maju.

Imelda, M.A. Jamal, dan Suyidno. (2013). Pengembangan Perangkat Pembelajaran IPA Fisika melalui Model Pembelajaran Inkuiri dengan Metode Pictorial Riddle. Berkala Ilmiah Pendidikan Fisika, 1(1), 31-39.

Kristianingsih, D.D, S.S. Sukiswo, dan S. Khanafiyah. (2010). Peningkatan Hasil Belajar Siswa melalui Model Pembelajaran Inkuiri dengan Metode Pictorial Riddle pada Pokok Bahasan Alat - alat Optik di SMP. Jurnal Pendidikan Fisika Indonesia, 6(2010), 10-13.

Mardiyan, R. (2012). Peningkatkan Keaktifan dan Hasil Belajar Siswa dalam Pembelajaran Akuntansi Materi Jurnal Penyesuaian pada Siswa Kelas XI IPS 3 SMA Negeri 3
Bukittinggi dengan Metode Bermain Peran (Role Playing). Jurnal Pakar Pendidikan, 10(2), 151-162.

Murti, P.R, E. Wiyono, dan A. Jamaluddin. (2015). Penerapan Model Pembelajaran Kooperatif Tipe TAI untuk Meningkatkan Aktivitas Belajar dan Kemampuan Kognitif Siswa Kelas X MIA 7 di SMA Negeri 1 Karanganyar pada Materi Pokok Fluida Statis. Prosiding, Seminar Nasional Fisika dan Pendidikan Fisika (SNFPF) yang diselenggarakan oleh Universitas Sebelas Maret tanggal 25 Juni 2015. Surakarta: Universitas Sebelas Maret.

Permatasari, D.I, Indrawati, dan A. Harijanto. (2016). Peningkatan Aktivitas dan Hasil Belajar IPAFisika Pada Siswa Kelas VIII C SMP Negeri 7 Jember Tahun Ajaran 2014/2015 dengan Model Inkuiri melalui Teknik Pictorial Riddle. Jurnal Pembelajaran Fisika, 5(3), 270-276.

Ratnasari, E, dan J. Maknun. (2015). Penerapan Model Pembelajaran Inkuiri Terbimbing (Guided Inquiry) untuk Meningkatkan Sikap Peduli terhadap Lingkungan pada Konsep Pencemaran Lingkungan di Kelas VII SMP Negeri 3 Sumber. Scientiae Educatia, 5(2), 1-9.

Sari, N, et al. (2017). Analisis Penggunaan Media Pembelajaran Untuk Meningkatkan Motivasi Peserta Didik Terhadap Pembelajaran Fisika Kelas XI MIPA 1 SMA Titian Teras Muaro Jambi. Jurnal Pendidikan Fisika dan Keilmuan (JPFK), 3(2), 110-112.

Sochibin, A, P. Dwijananti, dan P. Marwoto. (2009). Penerapan Model Pembelajaran Inkuiri Terpimpin untuk Peningkatan Pemahaman dan Keterampilan Berpikir Kritis Siswa SD. Jurnal Pendidikan Fisika Indonesia (JPFI), 5(2009), 96-101.

Susilawati, F, dan W. Darmadi. (2014). Perbandingan Hasil Belajar Fisika 
Jurnal Pendidikan Fisika dan Keilmuan (JPFK), 4 (1), 2018 - 12

Maghfira Febriana, Hasan Al Asy'ari, Bambang Subali, Ani Rusilowati

antara Metode Pictorial Riddle dan

Metode Demonstrasi dalam

Pembelajaran Inquiry Terbimbing pada Siswa Kelas VIII SMP Negeri 19

Palu. Jurnal Pendidikan Fisika

Tadulako (JPFT), 1(3), 8-12.

Syafura, D.T, Sahyar, dan W. Bunawan. (2017). The Effect of Scientific Inquiry Model Assisted Visual Media on Students' Conceptual and Procedural Knowledge. American Journal of Educational Research, 6(5), 623-628. 